\title{
G sck \\ Lack of association between vitamin D insufficiency and clinical outcomes of patients with COVID-19 infection
}

\section{Alireza Davoudi}

Antimicrobial Resistance Research Center, Communicable Diseases Institute, Mazandaran University of Medical Sciences, Sari, Iran

\section{Narges Najafi}

Antimicrobial Resistance Research Center, Communicable Diseases Institute, Mazandaran University of Medical Sciences, Sari, Iran

\section{Mohsen arabi}

Department of Family Medicine, School of Medicine, Mazandaran University of Medical Sciences, Sari, Iran

\section{Atefe Tayebi}

Antimicrobial Resistance Research Center, Communicable Diseases Institute, Mazandaran University of Medical Sciences, Sari, Iran

\section{Roja Nikaeen}

Department of Biostatistics, Faculty of Medical Sciences, Tarbiat Modares University, Tehran, Iran Hamideh Izadyar

Antimicrobial Resistance Research Center, Communicable Diseases Institute, Mazandaran University of Medical Sciences, Sari, Iran

\section{Zahra Salar}

Mazandaran University of Medical Science, Ramsar international branch, Ramsar, Iran

\section{Leila Delavarian}

Antimicrobial Resistance Research Center, Communicable Diseases Institute, Mazandaran University of Medical Sciences, Sari, Iran

\section{Narges Vaseghi}

Department of Pathobiology ,Science and Research Branch,Islamic Azad University,Tehran,Iran

\section{Zahra Daftarian}

Antimicrobial Resistance Research Center, Communicable Diseases Institute, Mazandaran University of Medical Sciences, Sari, Iran

Fatemeh Ahangarkani ( $\nabla$ fkani63@gmail.com )

Antimicrobial Resistance Research Center, Communicable Diseases Institute, Mazandaran University of Medical Sciences, Sari, Iran 


\section{Research Article}

Keywords: Vitamin D, SARS-CoV-2, COVID-19, Coronavirus, Sufficiency, insufficiency

Posted Date: December 18th, 2020

DOl: https://doi.org/10.21203/rs.3.rs-121748/v1

License: (c) (i) This work is licensed under a Creative Commons Attribution 4.0 International License. Read Full License 


\section{Abstract \\ Background}

A protective effect of vitamin D against COVID-19 is under investigation. We aimed to analyze the effect of vitamin D sufficiency on clinical outcomes of patients with COVID-19 infection.

\section{Methods}

In this retrospective study we analyzed the vitamin D levels of COVID-19 patients who were admitted to Razi Hospital (an infectious disease referral center in Mazandaran province in north of Iran) from February to March 2020. Overall, a cutoff point of $30 \mathrm{ng} / \mathrm{mL}$ was used for the definition of vitamin D sufficiency.

\section{Results}

153 patients were analyzed in this study who had laboratory documentation of a $25(\mathrm{OH}) \mathrm{D}$ level at the time of hospitalization. In total, $62.7 \%(\mathrm{n}-=96)$ of the patients had a $25(\mathrm{OH}) \mathrm{D}$ level of less than $30 \mathrm{ng} / \mathrm{mL}$ and $37.25 \%(n=57)$ had a $25(\mathrm{OH})$ D level of more than $30 \mathrm{ng} / \mathrm{mL}$. In total, $49 \%(n=75)$ of the patients suffered from at least one underlying disease. Vitamin $D$ sufficiency was not associated with a statistically significant lower risk of adverse clinical outcomes of COVID-19 such as duration of hospitalization, lung involvement, intensive care unit (ICU) admission, invasive and non-invasive ventilation, the severity of disease or death.

\section{Conclusions}

Sufficient vitamin $D$ levels were not found to be protective against adverse clinical outcomes in patients infected with COVID-19.

\section{Introduction}

Coronavirus 2019 or COVID-19, a respiratory infectious disease, has led to a pandemic of pneumoniarelated illness [1-3]. The clinical features of this disease vary from asymptomatic or mild (in over $80 \%$ ) to severe cases leading to acute respiratory syndrome and respiratory failure, requiring hospitalization in the intensive care unit, sepsis, septic shock and death [4-6]. The rapidly increasing number of infected individuals in highly critical states requiring intensive resources is a huge public health challenge worldwide [7]. Unfortunately, no suitable antiviral treatment has been found for this disease so far, and all therapeutics used are based on hypotheses that do not have sufficient evidence to support their use. In addition, a good vaccine is not yet commercially available for this viral infection, therefore given the high economic importance of the COVID-19 pandemic, it is necessary to find methods that reduce the risk of 
infection and mortality at a low cost [8]. The status of the immune system is affected by multiple factors that may contribute to the risk of viral infections such as COVID-19. There are several vitamins and essential elements that have been shown to be necessary for a robust immune system response [9]. Recent studies have highlighted a crucial supportive role for vitamin $D$ in immune system functions, particularly in balancing the inflammatory response to viral infection [9-11]. Vitamin $D$ is a fat-soluble vitamin that plays a key role in modulating both innate and adaptive immune responses. Previous studies have also shown that adequate levels of vitamin $D$ have been shown to reduce the risk of viral respiratory infections and the length of hospital stay $[1,12,13]$. On the other hand, there is no accurate information about the COVID-19 virus in this field and the role of vitamin D supplementation in reducing the risk of infection is still under evaluation. Furthermore, the role of vitamin D supplementation in reducing the risk of COVID-19 infection is still under investigation, however, no clinical evidence has been reported thus far [14]. Studies about the blood level of vitamin $D$ in Iran showed a significant prevalence of vitamin $D$ deficiency among the Iranian population $[15,16]$. Mazandaran province is located in the north of Iran, along the southern coast of the Caspian Sea with a moderate climate. In this study, we investigated the effect of vitamin D sufficiency on clinical outcomes of patients with COVID-19 infection hospitalized in Razi hospital (a referral center of COVID-19 patients in Mazandaran province).

\section{Materials And Methods}

This was a retrospective study analyzing vitamin D levels of COVID-19 patients who were admitted to Razi Hospital (an infectious disease referral center in Mazandaran province in north of Iran) from February to March 2020. The study was approved by the Ethics Committee of Mazandaran University of Medical Science, Ramsar international branch (IR.MAZUMS.RIB.REC.1399.019). In this study all applied methods were carried out in accordance with relevant guidelines and regulations. The definitive diagnosis of COVID-19 infection was based on a positive PCR test of the nasopharyngeal swab sample. A total of $3 \mathrm{cc}$ of whole blood was taken from each patient and the serum was removed and the vitamin $\mathrm{D}$ levels were measured by a high performance liquid chromatography method. Overall, a cutoff point of $30 \mathrm{ng} / \mathrm{mL}$ was used for the definition of vitamin D sufficiency [17]. All demographic, clinical, and diagnostic data of the patients and their vitamin $D$ levels were recorded. Definitions of disease severity were based on the Infectious Diseases Society of America guidelines on the treatment and management of patients with COVID-19 including : 1- Mild stage; 2- Non-severe or moderate (patient with a oxygen saturation (SpO2) >94\% not requiring supplemental oxygen); 3 - Severe stage (patients with $\mathrm{SpO} 2 \leq 94 \%$ on room air, including patients on supplemental oxygen; 4- Critical (patients on mechanical ventilation and extracorporeal mechanical oxygenation, acute respiratory distress syndrome, end organ dysfunction and sepsis/septic shock). Severe and critical categories were defined as "severe" in our study. Statistical analysis was performed using the Stata software version 14.0. Differences between groups (patients with serum level $25(\mathrm{OH}) \mathrm{D}$ level $\geq 30$ and patients with serum level $25(\mathrm{OH}) \mathrm{D}$ level $\leq 30$ ) were determined by the chi-square test or Fisher's exact test. Multivariable analysis was performed using logistic regression to identify the relationship of socio-demographic characteristics and preexisting comorbidities and the level of vitamin D with adverse outcomes of COVID-19. Ordinal logistic regression was used to determine the 
association between variables and severity of diseases. The descriptive values below $5 \%$ ( $P$ value $<0.05)$ were considered statistically significant. In cases with a statistically significant difference, adjusted odds ratios (ORs) with 95\% confidence intervals (Cls) were reported.

\section{Results}

A total of 841 patients with COVID-19 were admitted to Razi Hospital from February 2 to March 20, 2020, of which 153 patients were analyzed in this study who had laboratory documentation of a $25(\mathrm{OH}) \mathrm{D}$ level at the time of hospitalization. All patients had CT imaging findings typical of COVID-19 and a SARS-CoV2 PCR-positive result. In total, $62.7 \%(n=96)$ of the patients had a $25(\mathrm{OH})$ D level of less than $30 \mathrm{ng} / \mathrm{mL}$ and $37.25 \%(n=57)$ had a $25(\mathrm{OH})$ D level of more than $30 \mathrm{ng} / \mathrm{mL}$. To assess the role of vitamin $D$ status in relation to the disease, socio-demographic features, comorbidity factors, and clinical outcomes, all data were classified into two subgroups based on $25(\mathrm{OH}) \mathrm{D}$ levels. The socio-demographics and comorbidities and clinical outcomes of COVID-19 patients are presented in Tables 1 and 2. 
Table 1

Socio-demographics and Comorbidity of COVID-19 Patients Based on Vitamin D Level

\begin{tabular}{|c|c|c|c|c|c|c|c|}
\hline & & $\begin{array}{l}\text { Total } \\
(\mathrm{N}=153) \\
N(\%)\end{array}$ & $\begin{array}{l}25(\mathrm{OH}) \mathrm{D} \\
\text { level } \geq 30 \\
(\mathrm{~N}=57) \\
\mathrm{N}(\%)\end{array}$ & $\begin{array}{l}25(\mathrm{OH}) \text { D level } \\
\leq 30 \\
(\mathrm{~N}=96) \\
\mathrm{N}(\%)\end{array}$ & $\begin{array}{l}P \\
\text { value }\end{array}$ & $\begin{array}{l}\text { Odds } \\
\text { ratio }\end{array}$ & $95 \% \mathrm{Cl}$ \\
\hline Socio-de & graphic $c$ & laracteristic & & & & & \\
\hline Gender & Female & $\begin{array}{l}66 \\
(43.13)\end{array}$ & $23(40.35)$ & 43 (44.79) & 0.6 & NA & \\
\hline & Male & $87(53.86)$ & $34(59.64)$ & $53(55.2)$ & & & \\
\hline Age $>50$ & & $\begin{array}{l}98 \\
(64.05)\end{array}$ & 44 (77.19) & $54(56.25)$ & 0.009 & 2.63 & $\begin{array}{l}1.258- \\
5.509\end{array}$ \\
\hline $\begin{array}{l}\text { Body ma } \\
\text { (BMI) }\end{array}$ & index & $\begin{array}{l}29.909 \pm \\
5.81\end{array}$ & $29.15 \pm 5.71$ & $29.92 \pm 5.92$ & 0.32 & NA & \\
\hline Living & Rural & $57(37.25)$ & $20(35.08)$ & 37 (38.54) & 0.73 & NA & \\
\hline & Urban & $96(62.7)$ & $37(64.91)$ & $59(61.45)$ & & & \\
\hline Preexistir & comorbic & ties & & & & & \\
\hline Diabetes & & $41(26.79)$ & 19 (38.59) & $22(22.91)$ & 0.18 & NA & \\
\hline Hyperten & & $\begin{array}{l}44 \\
(28.75)\end{array}$ & $26(45.61)$ & 18 (18.75) & 0.001 & 3.63 & $\begin{array}{l}1.750- \\
7.549\end{array}$ \\
\hline $\begin{array}{l}\text { Cardiova } \\
\text { disease }\end{array}$ & ular & 30 (19.6) & $17(29.82)$ & $13(13.54)$ & 0.02 & 2.7 & $\begin{array}{l}1.201- \\
6.129\end{array}$ \\
\hline Dyslipide & & $10(6.53)$ & $1(1.75)$ & 9 (9.37) & 0.09 & NA & \\
\hline Hypothyr & dism & $9(5.88)$ & 0 & $9(9.37)$ & 0.02 & 0.906 & $\begin{array}{l}0.850- \\
0.966\end{array}$ \\
\hline Asthma & & $6(3.92)$ & 0 & $6(6.25)$ & 0.08 & NA & \\
\hline Malignan & & $3(1.96)$ & 2 & $1(1.04)$ & 0.55 & NA & \\
\hline $\begin{array}{l}\text { Chronic li } \\
\text { disease }\end{array}$ & & $2(1.3)$ & $1(1.75)$ & $1(1.04)$ & 1 & NA & \\
\hline $\begin{array}{l}\text { Chronic K } \\
\text { Disease }\end{array}$ & Iney & $1(0.65)$ & $1(1.75)$ & 0 & 0.37 & NA & \\
\hline
\end{tabular}

Based on age group patients were distributed in three groups including 35.94\% ( $n=55)$ less 50 years old, $34.64 \%(n=53)$ in the range $50-65$ years and $28.75 \%(n=44)$ more than 65 years old respectively; $58.2 \%$ $(n=89)$ of patients were male, and $41.8 \%(n=64)$ were female. Of the 98 patients who were 50 years and 
older, $56.25 \%$ had a blood level of $25(\mathrm{OH}) \mathrm{D}<30 \mathrm{ng} / \mathrm{mL}(\mathrm{p}=0.009)$. There were no differences between the two groups (patients with serum level $25(\mathrm{OH}) \mathrm{D}$ level $\geq 30$ and patients with serum level $25(\mathrm{OH}) \mathrm{D}$ level $\leq 30$ ) in regards to gender and living area. Most of the patients had multiple underlying disorders. The most common underlying illnesses were hypertension $26.8 \%(n=44)$, diabetes $26.8 \%(n=41)$, cardiovascular disease $19.6 \%(n=30)$, dyslipidemia $6.5 \%(n=10)$, hypothyroidism $5.9 \%(n=9)$, asthma $5.9 \%(n=9)$, malignancy $1.96 \%(n=3)$ and chronic liver disease $1.3 \%(n=2)$, respectively. In total, 49\% $(n$ $=75$ ) of patients suffered from at least one underlying disease. Significant differences between the two groups were noted to be preexisting comorbidities such as hypertension, cardiovascular disease, and hypothyroidism $(p<0.05)$. Hypertension $(17 / 30)$ and cardiovascular disease $(13 / 30)$ were mostly noted among patients with blood level $25(\mathrm{OH})$ D level $\geq 30 \mathrm{ng} / \mathrm{mL}$, while hypothyroidism was only seen in patients with blood level $25(\mathrm{OH}) \mathrm{D}$ level $\leq 30 \mathrm{ng} / \mathrm{mL}$.

Table 2

The COVID-19 Clinical Outcomes of Patients Based on Vitamin D Level

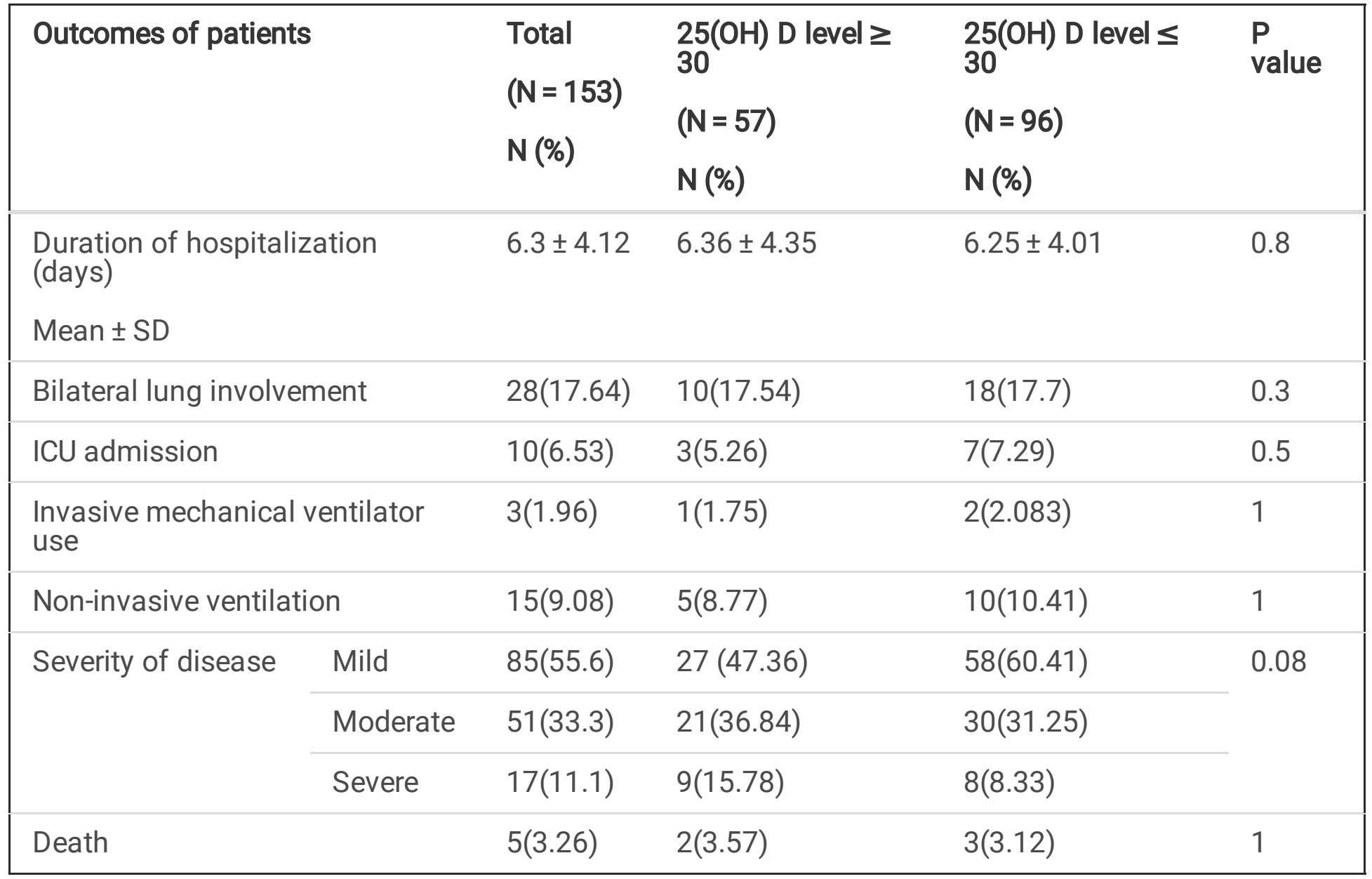

The average hospitalization stay of patients were $6.3 \pm 4.12$ days. Bilateral lung involvement was seen in $17.64 \%$ of patients. In total, $6.53 \%$ of patients were admitted to the ICU. Invasive mechanical ventilator was utilized for $1.96 \%$ of patients while $9.08 \%$ of patients were under non-invasive ventilation. Based on severity of disease, $55.6 \%$ of patients were categorized into the mild form of COVID-19 disease, while $33.3 \%$ and $11.1 \%$ experienced the moderate and severe / critical forms of COVID-19, respectively. Overall, $3.26 \%$ of patients involved expired. Vitamin D sufficiency was not associated with a statistically 
significant lower risk of adverse clinical outcomes of COVID-19 such as duration of hospitalization, lung involvement, ICU admission, invasive and non-invasive ventilation, severity of disease or death.

Ordinal logistic regression showed that male patients (OR 2.5, 95\% $\mathrm{Cl}(1.241,5.301), \mathrm{P}=0.011$ ) and patients with diabetes (OR 3.98, 95\% $\mathrm{Cl}(1.34,11.86), \mathrm{P}=0.013)$ experienced the severe form of COVID-19 infection more often than other patients. Multiple logistic regression showed that patients with cardiovascular disease were more at risk of requiring non-invasive ventilation (OR 4.37, $\mathrm{Cl}(1.44,13.26), \mathrm{P}$ $=0.009$ ). There was no significant association between other effective predisposing risk factors such as socio-demographic characteristics and preexisting comorbidities on the outcome of COVID-19.

\section{Discussion}

The association between vitamin $\mathrm{D}$ status and seasonal respiratory infections has been proven in several studies $[11,18,19]$. Optimizing vitamin $D$ status could improve the immune response and has been suggested as possibly protective in COVID-19 infection [20,21]. The COVID-19 outbreak began during the winter and a common feature of the inhabitants of all countries north of the 42 nd parallel is a vitamin D insufficiency [22]. These facts resulted in the concept of using vitamin D for the prevention of COVID-19 infection or using vitamin $D$ as an intervention strategy in COVID-19 patients $[3,18]$. In our study, only $37.25 \%$ of patients with documented COVID-19 infection had a sufficient blood level of vitamin D. However, after categorizing all patients based on a cutoff point of $30 \mathrm{ng} / \mathrm{mL}$ for $25(\mathrm{OH}) \mathrm{D}$ to assess the association between vitamin D sufficiency and severity of COVID-19 infection, we found a lack of effect of vitamin D insufficiency on clinical outcomes in patients with COVID-19 infection. Studies investigating the association of circulating levels of $25(\mathrm{OH}) \mathrm{D}$ and incidence and severity of COVID-19 are currently limited and prospective studies published to date are conflicting. Maghbooli et al. reported vitamin D sufficiency reduced the risk for adverse clinical outcomes in patients with COVID-19 infection, and Panagiotou1 et al. reported low serum 25(OH) D levels in patients hospitalized with COVID-19 are associated with greater disease severity $[12,13]$. Consistent with our study findings, the study by Hastie et al. did not support a potential link between vitamin D concentrations and risk of COVID-19 infection [20]. Older age and co-morbidities are linked to an insufficient vitamin D supply [23, 24]. It is notable that $64.05 \%$ of our patients were greater than 50 years old. Therefore the high rate of patients in our study with blood $25(\mathrm{OH})$ D level $\leq 30 \mathrm{ng} / \mathrm{mL}$ may be due to the aging population. Unlike our study, where the severity of COVID-19 infection was not associated with lower blood levels of 25(OH) D, Baktash et al. assessed the potential relationship between vitamin D deficiency and COVID-19 severity in hospitalized older adults and found that older patients with lower serum concentrations of $25(\mathrm{OH}) \mathrm{D}$, when compared with aged-matched vitamin D-replete patients, may demonstrate worse outcomes from COVID-19[23]. Moreover, a meta-analysis by Zhao et al. on 53000 COVID-19 patients, co-morbidities and old age showed a relationship with the renin angiotensin-aldosterone-system, vitamin D status and COVID-19 infection [25]. In our study, $19.6 \%$ of patients suffered from cardiovascular disease and after adjusting for sociodemographic features, comorbidity variables, and vitamin $\mathrm{D}$ level, multivariate logistic regression results have shown an increased need for ventilation in patients with cardiovascular disease. Other studies have shown increased risk of hospitalization stay and severe conditions requiring ventilation in patients with 
diabetes and hypertension $[20,26,27]$. Several studies have reported that a higher prevalence of vitamin D deficiency was observed in patients with worse COVID-19 outcomes [12-14, 28]. In our study, there was no evidence to suggest that assessment of vitamin $D$ can serve as an indicator of the outcomes of COVID-19 infection. In line with our findings, Hastie et al. reported that measurement of vitamin D would not be useful to evaluate the risk of COVID-19 in clinical practice [20].

\section{Conclusion}

Despite the fact that the number of patients with an insufficient blood level of vitamin $D$ were greater in our study, and approximately $44 \%$ of patients fell into the moderate and severe/critical categories, some requiring invasive/non-invasive ventilation, ICU admission, longer hospitalization and death, there was no statically significant evidence that insufficient blood levels of vitamin D might play a role in adverse outcomes of COVID-19 infection. Larger prospective studies are needed however to support or refute our observations.

\section{Abbreviations}

Odds ratio: OR; Confidence interval: Cl; Peripheral oxygen saturation:SPO2; Body mass index: BMl; Intensive care unit: ICU

\section{Declarations}

\section{Acknowledgements}

We thank all participants and staffs of this study at Razi teaching hospital affiliated to Mazandaran University of medical sciences.

\section{Authors' contributions}

$A D, N N$ and FA designed the project, collected data, wrote and performed the critical review of the manuscript. MA, AT, HI, ZS, LD, RN, NV and ZD contributed to clinical data collection. MA and RN carried out statistical interpretation. All authors read and approved the final manuscript.

\section{Funding}

Alireza Davoudi received Research grants of Ramsar international branch of Mazandaran University of Medical Sciences with grant number 7951.

\section{Availability of data and materials}

All data analysed during this study are included in this published article.

\section{Ethics approval and consent to participate}


This study was approved by the Ethics Committee of Ramsar international branch of Mazandaran University of Medical Sciences with code: IR.MAZUMS.RIB.REC.1399.019. In addition, written informed consent was obtained from all subjects or, if subjects are under 18, from a parent and/or legal guardian.

\section{Consent for publication}

Not applicable.

\section{Competing interests}

The authors declare that they have no competing interests.

\section{References}

1. Grant WB, Lahore H, McDonnell SL, Baggerly CA, French CB, Aliano JL, Bhattoa HP: Evidence that Vitamin D Supplementation Could Reduce Risk of Influenza and COVID-19 Infections and Deaths. Nutrients 2020, 12(4).

2. Guan WJ, Ni ZY, Hu Y, Liang WH, Ou CQ, He JX, Liu L, Shan H, Lei CL, Hui DSC et al: Clinical Characteristics of Coronavirus Disease 2019 in China. N Engl J Med 2020, 382(18):1708-1720.

3. Laird E, Rhodes J, Kenny RA: Vitamin D and Inflammation: Potential Implications for Severity of Covid-19. Irish medical journal 2020, 113(5):81.

4. Arabi YM, Fowler R, Hayden FG: Critical care management of adults with community-acquired severe respiratory viral infection. Intensive Care Med 2020, 46(2):315-328.

5. Li T: Diagnosis and clinical management of severe acute respiratory syndrome Coronavirus 2 (SARSCoV-2) infection: an operational recommendation of Peking Union Medical College Hospital (V2.0). Emerg Microbes Infect 2020, 9(1):582-585.

6. Rhodes JM, Subramanian S, Laird E, Kenny RA: Editorial: low population mortality from COVID-19 in countries south of latitude 35 degrees North supports vitamin $D$ as a factor determining severity. Aliment Pharmacol Ther 2020, 51(12):1434-1437.

7. Zheng Z, Peng F, Xu B, Zhao J, Liu H, Peng J, Li Q, Jiang C, Zhou Y, Liu S et al: Risk factors of critical \& mortal COVID-19 cases: A systematic literature review and meta-analysis. $J$ Infect 2020, 81(2):e16e25.

8. Wintergerst ES, Maggini S, Hornig DH: Contribution of selected vitamins and trace elements to immune function. Ann Nutr Metab 2007, 51(4):301-323.

9. Patel N, Penkert RR, Jones BG, Sealy RE, Surman SL, Sun Y, Tang L, DeBeauchamp J, Webb A, Richardson $\mathrm{J}$ et al: Baseline Serum Vitamin A and D Levels Determine Benefit of Oral Vitamin A\&D Supplements to Humoral Immune Responses Following Pediatric Influenza Vaccination. Viruses 2019, 11(10).

10. Beard JA, Bearden A, Striker R: Vitamin D and the anti-viral state. Journal of Clinical Virology 2011, 50(3):194-200. 
11. Mathyssen C, Aelbrecht C, Serré J, Everaerts S, Maes K, Gayan-Ramirez G, Vanaudenaerde B, Janssens W: Local expression profiles of vitamin D-related genes in airways of COPD patients. Respiratory Research 2020, 21:1-10.

12. Maghbooli Z, Sahraian MA, Ebrahimi M, Pazoki M, Kafan S, Tabriz HM, Hadadi A, Montazeri M, Nasiri $M$, Shirvani A et al: Vitamin D sufficiency, a serum 25-hydroxyvitamin D at least $30 \mathrm{ng} / \mathrm{mL}$ reduced risk for adverse clinical outcomes in patients with COVID-19 infection. PloS one 2020, 15(9): $\mathrm{e} 0239799$.

13. Panagiotou G, Tee SA, Ihsan Y, Athar W, Marchitelli G, Kelly D, Boot CS, Stock N, Macfarlane J, Martineau AR et al: Low serum 25-hydroxyvitamin D (25[OH]D) levels in patients hospitalized with COVID-19 are associated with greater disease severity. Clinical endocrinology 2020.

14. D'Avolio A, Avataneo V, Manca A, Cusato J, De Nicolò A, Lucchini R, Keller F, Cantù M: 25Hydroxyvitamin D Concentrations Are Lower in Patients with Positive PCR for SARS-CoV-2. Nutrients 2020, 12(5).

15. Larijani B, Hossein-Nezhad A, Feizabad E, Maghbooli Z, Adibi H, Ramezani M, Taheri E: Vitamin D deficiency, bone turnover markers and causative factors among adolescents: a cross-sectional study. Journal of diabetes and metabolic disorders 2016, 15:46.

16. Tabrizi R, Moosazadeh M, Akbari M, Dabbaghmanesh MH, Mohamadkhani M, Asemi Z, Heydari ST, Akbari M, Lankarani KB: High Prevalence of Vitamin D Deficiency among Iranian Population: A Systematic Review and Meta-Analysis. Iranian journal of medical sciences 2018, 43(2):125-139.

17. Holick MF, Binkley NC, Bischoff-Ferrari HA, Gordon CM, Hanley DA, Heaney RP, Murad MH, Weaver CM: Evaluation, treatment, and prevention of vitamin D deficiency: an Endocrine Society clinical practice guideline. J Clin Endocrinol Metab 2011, 96(7):1911-1930.

18. Jolliffe D, Camargo CA, Sluyter J, Aglipay M, Aloia J, Bergman P, Damsgaard C, Dubnov-Raz G, Esposito S, Ganmaa D: Vitamin D supplementation to prevent acute respiratory infections: systematic review and meta-analysis of aggregate data from randomised controlled trials. MedRxiv 2020 .

19. Xu J, Yang J, Chen J, Luo Q, Zhang Q, Zhang H: Vitamin D alleviates lipopolysaccharide-induced acute lung injury via regulation of the renin-angiotensin system. Molecular medicine reports 2017, 16(5):7432-7438.

20. Hastie CE, Mackay DF, Ho F, Celis-Morales CA, Katikireddi SV, Niedzwiedz CL, Jani BD, Welsh P, Mair FS, Gray SR et al: Vitamin D concentrations and COVID-19 infection in UK Biobank. Diabetes \& metabolic syndrome 2020, 14(4):561-565.

21. Martineau AR, Forouhi NG: Vitamin D for COVID-19: a case to answer? The Lancet Diabetes \& Endocrinology 2020, 8(9):735-736.

22. Biesalski HK: Vitamin D deficiency and co-morbidities in COVID-19 patients-A fatal relationship? NFS Journal 2020.

23. Baktash V, Hosack T, Patel N, Shah S, Kandiah P, Van Den Abbeele K, Mandal AKJ, Missouris CG: Vitamin D status and outcomes for hospitalised older patients with COVID-19. Postgraduate medical 
journal 2020.

24. Ghasemian R, Shamshirian A, Heydari K, Malekan M, Alizadeh-Navaei R, Ebrahimzadeh MA, Jafarpour H, Shahmirzadi AR, Khodabandeh M, Seyfari B: The Role of Vitamin D in The Age of COVID-19: A Systematic Review and Meta-Analysis Along with an Ecological Approach. medRxiv 2020.

25. Zhao X, Zhang B, Li P, Ma C, Gu J, Hou P, Guo Z, Wu H, Bai Y: Incidence, clinical characteristics and prognostic factor of patients with COVID-19: a systematic review and meta-analysis. MedRxiv 2020.

26. Petrilli CM, Jones SA, Yang J, Rajagopalan H, O'Donnell LF, Chernyak Y, Tobin K, Cerfolio RJ, Francois F, Horwitz LI: Factors associated with hospitalization and critical illness among 4,103 patients with COVID-19 disease in New York City. MedRxiv 2020.

27. Richardson S, Hirsch JS, Narasimhan M, Crawford JM, McGinn T, Davidson KW, Barnaby DP, Becker LB, Chelico JD, Cohen SL: Presenting characteristics, comorbidities, and outcomes among $\mathbf{5 7 0 0}$ patients hospitalized with COVID-19 in the New York City area. Jama 2020.

28. Ilie PC, Stefanescu S, Smith L: The role of vitamin D in the prevention of coronavirus disease 2019 infection and mortality. Aging Clinical and Experimental Research 2020:1-4. 